\title{
Отражение истории, культуры и традиций Боснии в языке и фразеологии
}

\author{
М. С. ХМЕЛЕВСКИЙ \\ Кафедра славянской филологии, Санкт-Петербургский государственный университет, \\ Университетская наб., 11, RU-199034 Санкт-Петербург \\ E-mail: chmelevskij@mail.ru
}

(Received: 26 March 2015; accepted: 11 June 2015)

\begin{abstract}
The modern phraseology of Bosnian Muslims is one of unknown destinations in Balkan Slavonic linguistics. In this region, we recognize international and specific points, which illustrate different processes in history, culture, and traditions of Bosnia. We pay special attention to tracks of Slavonic, Eastern, and European cultures; Orthodox, Catholic, and Muslims mentalities in lexicology, phraseology, and slang. Materials for this research were taken from the personal interviewing of citizens during our visits to Bosnia from 2007 to 2014.

Keywords: phraseology, fixed comparisons, Bosnian Muslims, culture, history
\end{abstract}

Сараево - один из крупнейших политических, экономических и культурных центров Балканского полуострова, столица современной Боснии и Герцеговины, родины славян-мусульман, православных и католиков. История города Сараево и сараевской культуры уходит в глубь столетий: уже с XIII века этот город являлся средоточием различных влияний, приходивших на Балканы со всех концов света, которые преломлялись в нем, подстраиваясь под систему ценностей местного славянского населения с балканским менталитетом, и приживались здесь, переплетаясь с коренными традициями и устоями, что в результате придало неповторимый колорит не только самому городу, но и всему центрально-балканскому региону. Благодаря соединению в одном городе восточной мусульманской, западной католической, православной византийской и иудейской культур Сараево получило второе метафорическое название Evropski Jeruzalem.

Сараево как центр Боснии и Герцеговины изначально являлся не только своеобразным связующим мостом между Востоком и Западом, кроме всего прочего, он давно уже получил славу и богемного города: в нем издревле находили приют люди искусства, писатели, поэты, мыслители, композиторы, барды, режиссеры и актеры, прославившие свой город на все Балканы и далеко за их пределами. Благодаря неповторимой атмосфере и уникальности как самого города, так и всей Боснии, впитавшей и соединившей в себе многообразную и пеструю палитру традиций, различных религиозных течений, всем народам Южной Славии хорошо известно и вариативно обыгрывается шутливое фразеологизированное выражение Nema zemlje /Ne znam zemlju koja Bosne neта 'Это не страна / Я не знаю страны, если в ней нет Боснии'. Или: 
Mani zemlju koja Bosne nema (с расширением: ... č čoveka što kraj žene drema) 'Избегай/сторонись той страны, в которой нет Боснии (...и того мужчины, что рядом с женщиной дремлет) ${ }^{2}{ }^{1}$ Чаще всего оно иронично и с любовью употребляется с пейоративным глаголом: jeběs zemlju koja Bosne nema! 'знать не хочу страну/не признаю страны/нет такой страны, в которой нет Боснии'. Это выражение можно услышать не только в Боснии, но и в Сербии, Хорватии, Черногории, оно давно приобрело статус шутливого постоянного эпитета Боснии, которая в сознании представителей Южной Славии является той неотделимой жемчужиной, без которой весь славяно-балканский регион потерял бы свою специфику и уникальность.

В качестве еще одной и, возможно, главной особенности Боснии и Герцеговины справедливо подчеркивается ее конфессиональное многообразие. Вплоть до Х века местное население оставалось языческим, и хотя христианство проникло сюда сравнительно рано (к XIV веку здесь уже сосуществовали православие и католичество), довольно долгое время на территории Боснии и Герцеговины были широко распространены и богомильство, и своеобразная боснийская церковь. А позднее, с приходом турок на Балканы, значительная часть местного славянского населения начинает принимать ислам. B XV веке Босния окончательно попадает под власть Османской империи, и данный исторический факт находит в языке отражение в виде фразеологизма pade Bosna ko dozrelo jabuko u sultanovo krilo 'пала Босния, как созревшее яблоко, в объятия султана', который в современном языке употребляется в значении 'свершилось что-либо неминуемое и заранее предрешенное, чему невозможно противостоять' (ср. рус. чему быть - того не миновать). О том, как религия мусульман приживалась в Боснии и подстраивалась под нравы, устои и традиции местного славянского населения, образно свидетельствует и поговорка, дошедшая до наших дней еще с тех времен: Bosna je potekla šerbetom, ali i muselezom 'И потекли по Боснии не только шербет, но и вино' (šerbet - 'вода, подслащенная медом', muselez - 'слабое вино из недозрелого винограда'). Пословица хранит в себе образ пришедшего вместе с исламом запрета на употребление алкогольных напитков, которые «помутняют дух и разум», но, с другой стороны, подмечает и стремление боснийцев сохранить привычный уклад жизни, традиции виноделия, а в переносном значении 'желание принять новое, сохранив при этом и старое'. Пословица употребляется и в значении обратной реакции: 'в ответ на запрет алкоголя боснийцы стали выпивать больше'. О верности своим исконным обычаям свидетельствует и укоренившаяся в языке ироничная пословица religije se mijenjaju, pivo i vino ostaje 'религии меняются, а пиво и вино остаются', в которой отражаются исторические процессы перехода южных славян из одной веры в другую. Отголоски этих процессов можно наблюдать в Боснии и сегодня.

1 Здесь и далее примеры собраны нами у информантов (носителей языка, коренных жителей Боснии и Герцеговины) в ходе научных экспедиций и полевых исследований в Боснии и Герцеговине в период с 2007 по 2014 гг.

Studia Slavica Hung. 60, 2015 
А современный жаргонный фразеологизм musliman na baterije 'мусульманин на батарейках' высмеивает человека, который еще совсем недавно пускался во все тяжкие грехи, а сейчас открыто демонстрирует свою ярую приверженность аскетическим канонам ислама.

B XV веке в ислам переходит около $40 \%$ населения Боснийского санджака (административный статус Боснии и Герцеговины в составе Османской империи). Среди обращенных в ислам, в частности, немало представителей аристократической элиты, которые добровольно принимали новую религию, стремясь таким образом сохранить свои привилегии, получить возможности карьерного роста, дать своим детям достойное образование в Стамбуле. О таком историческом факте принятия ислама не под натиском завоевателей, а с целью сохранения или получения положения в обществе, новых земельных владений и привилегий, уподобившись большинству, добровольно и безропотно разделив судьбу своего народа, свидетельствует фразеологизм, который употребляется у всех южнославянских народов: Kud svi Turci, tud i mali Мијо 'Куда все турки, туда и маленький Муйо' (Муйо - распространенное среди боснийцев мужское имя, сокращенное от Myстафа, а у хорватов, сербов и черногорцев в разговорной речи, включая анекдоты, оно употребляется как нарицательное для наименования боснийца). Данная пословица требует небольшого комментария: в ней имеются в виду не столько турки, сколько сами боснийцы, т. е. славяне, принявшие ислам, которых довольно долгое время соседние южные славяне (православные и католики) называли турками.

В результате данного исторического процесса распространения ислама среди балканских славян наряду с миром Slavia Ortodoxa и Slavia Latina на Балканах формируется еще один Славяно-мусульманский мир, который в настоящее время насчитывает около 1,8 млн. человек. На религиозном принципе, имевшем главное значение для формирования и становления отдельных народов Южной Славии, в XV веке на Балканах зарождается новая нация славян-мусульман, боснийских сербов-мусульман, бошняков, именующих себя Muslimani. Данный этноним в Южной Славии употребляется не столько для конфессионального определения, сколько в качестве наименования славянского населения, исповедующего ислам, в результате чего данный народ выделился из общей массы других южнославянских народов. Так, особенно в регионах со смешанным этническим народонаселением, довольно часто можно услышать, например: u uvom selu žive Srbi, Hrvati i Muslimani 'в этой деревне проживают сербы, хорваты и мусульмане', т. е. три славянских народа, исповедующих три различные религии.

Равно как и остальные славяне с принятием христианства наследовали или перенимали византийскую или римскую культуру, так и славяне-мусульмане вместе с исламом впитывали в себя культуру и традиции Востока, в первую очередь, пришедшую из культурно-религиозного центра того времени Стамбула, а также восточную мудрость, литературу, музыку, культуру, предметы быта, уклад жизни, менталитет. Все это до сих пор находит отражение в живом языке, фразеологии, устойчивых сочетаниях и сравнениях, языковых 
штампах и жаргоне. Вместе с исламом в Боснию приходит и новая письменность. Так, в период с XV по начало XX в. в Боснии, помимо кириллицы и латиницы, получает широкое распространение т. н. arebica/arabica, или таtufovača (письмо, названное по имени реформатора Мехмеда Джемалудина Чаушевича, сокращенно - Mamyф), или mektebica (от mekteb 'высшая школа'), т. е. созданное на основе арабской вязи для записи славянской речи специфичное боснийское письмо, на котором в течение пяти веков писались не только религиозные, но и художественные, поэтические произведения, юридические документы.

Вполне очевиден тот факт, что результатом исламизации славянского населения Балкан стало проникновение в их язык и значительного числа турцизмов и арабизмов, поскольку на протяжении довольно долгого времени официальными служебными языками являлись турецкий и арабский, а языком литературы и поэзии - персидский. Находясь под властью Османской империи, все южные славяне, в том числе православные и католики, в той или иной степени заимствуют турцизмы на всех уровнях языка, их распространенность и частотность употребления в живой речи можно проследить на всей территории проживания балканских славян. На пути данной изоглоссы от востока с постепенным затуханием к западу возникает боснийский ареал, где употребление турцизмов выражено наиболее явно по сравнению со всем остальным южнославянским регионом (зачастую даже при наличии синонимичного славянского эквивалента предпочтение отдается турцизму).

Так, к примеру, наряду с интернациональными фразеологическими единицами, которые встречаются во всех европейских языках - kralju kraljevo, caru carevo, bogu božje (ср. pус. Кесарю Кесарево) - в Боснии нередко можно встретить и варианты данной модели со специфичными для рассматриваемого региона компонентами: agi agino (aga - 'вождь, правитель'), begu begovo (beg - 'старший, главный правитель'), или, например, вариант hadžiji hadžijino, a meni moje (hadžija - 1. 'мусульманский паломник'; 2. 'лицо, наделенное властью'; 3. 'праведный человек', причем в жаргоне данная лексема часто употребляется в переносном значении: 'богатый, знатный, влиятельный, выделяющийся каким-л. качеством человек'). Этот компонент в последнем значении встречается и в таком устойчивом сочетании, как Ili si bos, ili si hadžija 'Или ты бос, или хаджия’ (ср., например, рус. Или пан, или пропал). При этом следует отметить, что и в сербских, и в хорватских СМИ, равно как и в разговорной речи, данное выражение дополняется уточнением: ...kako se u Bosni kaže 'как говорят в Боснии'. Употребительность данного фразеологического сочетания подтверждается еще и тем, что в современном молодежном языке оно может иронично обыгрываться благодаря совпадению по звучанию прилагательного bos 'босой' с англицизмом боcс, в результате чего возникает игра слов.

В продолжение темы обыгрывания данного фразеологического сочетания можно привести еще один пример из жаргонного употребления с пейоративным компонентом: jebe se tebi što je hadžija bos 'плевать тебе, что хаджия 
босой'. Выражение употребляется в ситуации, когда говорящий потерял все, что имел, и ему не от кого ждать помощи в трудном положении, а окружающим, мягко говоря, «наплевать» на то, что некогда состоятельный и всеми уважаемый человек остался без ничего.

Вышеприведенные примеры иллюстрируют процесс актуализации заимствованного слова в силу экстралингвистических причин путем попадания в интернациональную фразеологическую модель, которое начинает функционировать в языке «своей жизнью», порождая все новые значения и вариации, вплоть до переносных и жаргонных. В этой связи приведем такой фразеологизм, как oči kao fildžani - о больших (от удивления или страха) глазах. Здесь fildžan (ср. славянский аналог čaša, šolja) - слово, пришедшее из турецкого языка в значении 'стакан, чашка, кружка, чаша'. С тем же компонентом встречается еще один фразеологизм: gledati u fildžan 'смотреть в кофейную чашку' (ср. рус. гадать на кофейной гуще, срб. и хрв. gledati и šolju), где fildžan употреблено в значении традиционной боснийской кофейной чашки, которую в Боснии подают на медном подносе вместе с туркой, стаканом воды и рахат-лукумом и которая является неотъемлемым и повсеместным атрибутом боснийской традиции длительного и вдумчивого процесса пития кофе с множеством ритуалов, в том числе и последующим гаданием. Следует также упомянуть, что fildžan в сараевском жаргоне - это еще и спортивный кубок, это слово широко употребляется в ироническом фразеологическом сочетании в значении “дворовое футбольное соревнование’: Fildžan liga, и также иронично переносится на профессиональный футбол: Fildžan liga UEFA, Bundes fildžan liga и т. п.

Как видно из примеров, турцизмы выступают как частый компонент в устойчивых сочетаниях, в особенности с экспрессивным оттенком. Приведем еще один пример с турецким по происхождению словом megdan, которое в современном языке употребляется в следующих значениях: 1. 'открытое пространство в городе'; 2. 'поединок, единоборство, зрелище на городской площади'. Знакомое и сербам, и хорватам, это слово актуализируется в разговорной речи боснийцев, например, в таком фразеологизме, как biće (ima) dana za megdana ‘будет (есть) время для поединка' (с расширением устойчивого словосочетания: ... i pokoju čaršiju 'и для покоя на центральной городской улице'), который употребляется в значении 'время все расставит на свои места, еще пробьет мой час'. Или, например: ne može se megdan zadobiti na divanu sve lulu pušeći - букв. 'нельзя выиграть битву лежа на диване и покуривая трубку' (в значении - 'нельзя сидеть сложа руки').

В данной связи также любопытно проанализировать и такие фразеологические сочетания, в которых одним из компонентов выступают турцизмы, употребляемые исключительно в среде славян-мусульман и отражающие особенности их менталитета, образа жизни и конфессиональной принадлежности. Так, с принятием ислама в язык попадает заимствование bajram, обозначающее мусульманский религиозный праздник (cp. у католиков-славян blagdan 'католический праздник'), а в разговорной речи оно употребляется 
для названия любого праздника вообще. Причем, данный компонент легко укладывается в существующие интернациональные фразеологические модели: budali je svaki dan bajram 'дураку каждый день праздник', ni bajrami nisu što su bili 'даже святые праздники уже не те, что были раньше' (говорится о ностальгии по старым временам). Местный колорит отражает и фразеологизм с компонентом šenluk 'бал, веселье, процесс отмечания праздника': kad je šenluk, nek je šenluk! (по модели kad je bal, nek je bal), с вариантами второй части: kad je šenluk, nek $i$ hala gori 'когда праздник, пусть хоть и зал горит' или kad je šenluk, nek izgori i džamija 'когда праздник, пусть хоть и мечеть горит'.

Турцизму rahatluk трудно подобрать славянский эквивалент, поскольку это слово служит для обозначения концептуального для боснийской (и шиpe - южнославянской балканской) культуры понятия, объединяющего в себе состояние удовлетворения и удовольствия, полной расслабленности, беззаботности, умиротворения, неги. Наши информанты описывали его так: пероpisivi osjećaj opuštenosti, pokoja, bezbrižnosti, odnosno nirvana 'неописуемое ощущение расслабленности, беззаботности или нирвана'. Этот компонент встречается в таких устойчивых сочетаниях как bez zdravlja nema rahatluka 'без здоровья нет рахатлука', или: Bosanac nađe rahatluk i na kraju svijeta 'босниец найдет рахатлук даже на краю света'. В Боснии также довольно частотным является употребление однокоренного прилагательного rahat 'спокойный, уютный' (в турецком языке: ‘удобный, уютный, прелестный'): osjećao sam se kao golub, znači rahatno i lagahno 'я чувствовал себя, как голубь, то есть приятно, вольготно и легко'; rahatno pričati 'говорить сладкие речи'; Sarajevo je mirno i turist može rahatno hodati gradom 'Сараево - спокойный город, и туристы могут спокойно, получая наслаждение, гулять по нему'; rahatno dijete 'хорошенький, милый ребенок' (ср. эквивалент slatko dijete). Того же корня слово для названия восточных сладостей, необыкновенно популярных в Боснии, rahatlokum (тур. букв. 'прелестный кусочек'). Этот корень встречается во фразеологизме ni lokum više nije rahat, возникшем в результате языковой игры и повествующем о ностальгии по былым временам.

Еще один турцизм deredža 'религиозное положение' иллюстрирует процесс выхода слова за рамки сугубо религиозной сферы и расширения сферы его использования в живой речи, например, в качестве компонента во фразеологизме dobar/pošten/pametan i budala/glup su na istoj deredži 'добрый/ уважаемый/умный и дурак/глупый - все в одном положении'. Речь идет об уравнивании в правах разных по своим способностям и характеристикам людей. Данный фразеологизм в современном языке обрастает многочисленными вариантами типа Pariz i Sarajevo su na istoj deredži 'Париж и Сараево на равных правах', причем первая часть может свободно варьироваться: lud i hrabar 'сумасшедший и смелый', dobar i jeban 'хороший и придурковатый', zdravi hodža i zdravi hamal 'здоровый ходжа и здоровый чернорабочий', sva božija stvorenja kod Alaha 'все божии твари у Аллаха'. Фразеологизм с компонентом-турцизмом создан по устойчивой модели na istoj su liniji 'на одной 
линии', na istoj su razini 'на одном уровне', na istoj su stazi 'на одном пути', na istoj su strani 'на одной стороне' и т. п.

В рамках рассматриваемой темы нельзя не упомянуть и о такой характерной для разговорной речи южных славян категории, как устойчивые фразеологизированные заклятия. Наряду с общими для всех южных славян заклятиями boga mi 'богом клянусь', života mi 'жизнью клянусь' (чаще употребляется в Сербии, чем в Хорватии), в Боснии также не редко можно услышать такие словосочетания-штампы как Alaha mi, pojma ti nemaš o tome! 'Аллахом клянусь, ты в этом ничего не понимаешь!'; Dolazim ja, rahmeta mi 'Я приду, клянусь покоем усопшего'; и даже с повторением компонента для усиления экспрессии: Kunem se Alahom i rahmetom, istina je to! 'Клянусь Аллахом и усопшим, это правда!'. По той же модели функционирует и такое устойчивое сочетание-заклятие, как Tite mi! 'Клянусь Тито!'. Данный пример требует особого комментария. Иосип Броз Тито - президент бывшей Югославии в период с 1953 по 1980 гг. Его личность и его имя до сих пор вызывает многочисленные споры, оно овеяно мифами и, как следствие, живет в разговорном языке на всей территории Южной Славии - от Любляны до Скопье. Однако, по нашим наблюдениям, особенно часто имя, образ, миф и стереотип о И. Б. Тито упоминаются именно в Боснии, где заклятие Tite mi более употребительно, чем в Загребе или Белграде, что подтверждают и наши информанты.

Говоря о специфике живой речи в Боснии, нельзя не упомянуть и устойчивые слова, фразы, используемые при обращениях. Так, например, помимо распространенных и в Сербии, и Черногории, и Хорватии устойчивых обращений druže, brate, kuте и т. д. в речи боснийцев особой частотностью отличаются такие, как Zdravo, jarane! 'Привет, друг, приятель'. Исконно jaran слово турецкого происхождения, которое еще со времен Османской империи обозначало надежного человека, у которого можно скрыться от неприятеля. Но в современном разговорном языке его значение расширилось, исконная мотивировка стерлась, и оно превратилось почти в синоним для слова друг. И хотя эта лексема известна и в Сербии, и Хорватии, наибольшей частотностью употребления оно отличается именно в Боснии: Gdje si, jarane moj dragi?! - фраза-обращение, которая понятна жителю и Белграда, и Загреба, однако ассоциативно всегда связывается с регионом Боснии и Герцеговины. Наши информанты, поясняя употребление данного слова, отмечали: Jaran je drug, prijatelj... tako se kaže u Bosni 'Это приятель, друг... так говорят в Боснии'. Более того, только в Боснии встречается форма этого слова jaranica и по отношению к женщине, подруге, а в ироничном контексте иногда употребляется о ветреной, веселой и беззаботной девушке: svakog dana je dovodio novu jaranicu.

Именно с регионом Боснии и Герцеговины как у сербов, так и хорватов часто соотносится обращение к мужчине brko (Kako si, moj brko?!; Čuješ me, $b r k o$ ?). Первое значение слова $b r k$ - 'ус', которое в разговорной речи употребляется в значении 'усатый человек, усач'. Причем часто внутренняя мотивировка данного слова утрачивается, и прежде всего в формах обращения 
используется в качестве метафоры для обозначения любого лица мужского пола. Слово $b r k$ 'ус' известно как в Сербии, так и Хорватии, однако в качестве обращения к человеку его употребляют в основном в Боснии. Обращение dušmane moj в ироническом контексте также можно услышать на улицах Сараево со стертой мотивировкой в значении доброжелательного и ироничного обращения к другу (исконно dušman - 'враг, неприятель'). Еще один пример из культуры обращений в Боснии - употребление собирательного существительного raja (исконно оно означало 'христианин, подданный, плативший дань Турции'), которое в современном языке утратило свою мотивировку и функционирует в значении 'моя компания, мое общество, мои друзья': Gdje јe ta vaša sarajevska raja?, stara mektebska raja 'старые школьные товарищи' (ср. тур. mekteb 'школа'), а также в обращении: Pa, gdje ste, raja?! Информанты из Сербии, Черногории и Хорватии отмечали, что данная лексема им знакома и понятна, однако почти все опрошенные нами носители языка соотносили данное употребление с регионом Боснии и Герцеговины.

Фразеология славян-мусульман может быть отнесена к региональной, однако специфика локально ограниченного языка Боснии заключается в том, что родным все же остается более широкий языковой славянский субстрат. При этом в нем функционируют присущие только ему своеобразные черты в силу специфики и своеобразия культуры рассматриваемого региона. Здесь следует заметить, что многое из лексики и фразеологии Боснии, в основном, благодаря популяризации боснийской культуры, литературы, поэзии, сараевской бардовской песни и кино выходит за рамки данного микроареала и становится понятным далеко за его пределами, сохраняя при этом свою маркированность и соотнесенность с местом происхождения, т. е. с Боснией.

Вышесказанное подтверждают также и результаты опросов о восприятии приведенных в данной статье примеров. Большую часть описанных употреблений наши информанты охарактеризовали как «я понимаю, но воспринимаю, как боснийское», «сам не употребляю, но понимаю», или: «tako se kaže samo u Bosni» или «То si ti u Bosni čuo?», «Tо je bosanski izraz» и т. п. Причем, как в процессе сбора материала, так и при опросах нами принципиально выбирались носители языка без лингвистического образования для получения максимально объективных выводов без политизации рассматриваемого языкового материала.

\section{Литература}

Halilović-Tanović-ŠEhović 2009 = Halilović S., TANović I., ŠEhović A. Govor grada Sarajeva i razgovorni bosanski jezik. Sarajevo, 2009.

SARAČEVIĆ 2009 = SARAČEVIĆ N. Rječnik sarajevskog žargona. Zenica, 2009.

TANOVIĆ 2000 = TANOVIĆ I. Frazeologija bosanskog jezika. Sarajevo, 2000. 